\title{
A study on active management of third stage of labour as per WHO guidelines: efficacy and complications
}

\author{
Manthan M. Patel*, Mahima Jain \\ Department of Obstetrics and Gynaecology, PDU medical college, Rajkot, Gujarat 360001, India \\ Received: 23 October 2015 \\ Accepted: 10 December 2015 \\ *Correspondence: \\ Dr. Manthan M Patel, \\ E-mail: drmanthanpate1111@gmail.com \\ Copyright: ( $)$ the author(s), publisher and licensee Medip Academy. This is an open-access article distributed under \\ the terms of the Creative Commons Attribution Non-Commercial License, which permits unrestricted non-commercial \\ use, distribution, and reproduction in any medium, provided the original work is properly cited.
}

\begin{abstract}
Background: the objective of the study was to evaluate efficacy and complications of AMTSL as per WHO guidelines.

Methods: A total of 100 low risk patients assigned randomly at obstetrics department, P.D.U. medical college, Rajkot. Hundred women received i.m. oxytocin $10 \mathrm{IU}$ at the delivery of anterior shoulder of the baby, received uterine massage and delivery of placenta by controlled cord traction and blood loss is measured.

Results: Mean blood loss is $119 \mathrm{ml}$. One case had blood loss $>500 \mathrm{ml}$. Mean duration of third stage of labour is 5.16 minutes. Mean time taken by uterus to contract was 3.8 minutes.

Conclusions: AMTSL must be employed for prevention of postpartum haemorrhage (PPH) as advised by W.H.O. AMTSL as a routine protocol significantly brings down incidence of PPH.
\end{abstract}

Keywords: Oxytocin, Active management of third stage of labour (AMTSL), Postpartum haemorrhage PPH, Blood loss

\section{INTRODUCTION}

\section{Maternal mortality}

Taj mahal - One of the Seven Wonders of the World. One of the greatest monuments, dedicated to the memory of "Queen Mumtaz "who died after her last childbirth of postpartum haemorrhage in 1630 -is a testimony to grim reminder of the tragedy of maternal mortality that can befall any woman in childbirth. ${ }^{1}$ The World Health Organization states that every minute, at least one woman dies from complication related to pregnancy or childbirth that means 529000 women a year. ${ }^{2}$ Developing countries account for $99 \%$ (286 000) of the global maternal deaths with sub- Saharan Africa region alone accounting for 62\% (179 000) followed by Southern Asia (69 000). (Trends in maternal mortality: $1990-2013$ by W.H.O, UNICEF) The main direct causes of maternal death include Postpartum-hemorrhage (PPH), Sepsis,
Eclampsia, Unsafe abortion, and Obstructed labor. PPH is the leading single direct cause of maternal mortality, accounting for a quarter of all maternal deaths worldwide and causing approximately 140,000 deaths annually.,4

Khan et al, using various datasets, estimated that hemorrhage is the main cause of maternal mortality in Asia and Africa - accounting for $30 \%$ or more of all maternal deaths. "If mother receives postpartum care as assiduously as they receive prenatal care, maternal mortality would decrease."-Li et al in 1996. ${ }^{5}$ Atonic PPH is the most common cause of PPH and the leading cause of maternal death. To prevent atonic PPH, interventions should therefore be targeted at all women during childbirth. To reduce blood loss after delivery, the WHO recommends the Active Management of the Third Stage of Labor (AMTSL) be offered to all women delivering with skilled attendants (WHO 2007). ${ }^{6,7}$ 


\section{Prevention of $\mathrm{PPH}^{8,9}$}

Reaffirming and Refining Best Practice for PPH Prevention. (WHO 2012 Recommendations) Active management of the third stage of labour (AMTSL) is still a best practice, with the use of uterotonics now the most critical element. Oxytocin remains the uterotonic of choice for AMTSL. Oxytocin (10 IU, IM or IV) is the preferred uterotonic based on studies on the safety and effectiveness of uterotonics. Other elements of AMTSL - controlled cord traction and immediate fundal massage - are optional for PPH prevention. Delayed cord clamping (performed after 1 to 3 minutes after birth) is still recommended for all births to reduce infant anaemia - while beginning essential newborn care at the same time. Postpartum abdominal uterine tonus assessment for early identification of uterine atony is recommended for all women. Compared with physiologic management, active management of the third stage of labor reduced the risk of $\mathrm{PPH}$, the need for blood transfusion, the incidence of prolonged third stage (longer than $30 \mathrm{~min}$ ), and the need for additional therapeutic uterotonic drugs in all three trials..$^{10,11,12}$

\section{Assessments of blood loss ${ }^{13-17}$}

The BRASSS-V drape was developed by the NICHDfunded Global Network UMKC/ JNMC/UIC collaborative team to specifically estimate postpartum blood loss. (The name 'BRASSS-V' was coined by adding the first letter of the names of the seven collaborators who developed the drape.) The drape has a calibrated and funnelled collecting pouch, incorporated within a plastic sheet that is placed under the buttocks of the patient immediately after the delivery of the baby. Use of the drape diagnosed postpartum haemorrhage four times as often as the visual estimate.

\section{METHODS}

The study was conducted at Department of Obstetrics \&Gynaecology, P D U Medical College, Rajkot, from 5th Jan 2014 to 4th Jan2015. Ethical committee approval was taken. Low risk women were included in the study.

\section{Inclusion criteria}

Normal /low risk patients assigned randomly in age group of 19-35 years.

- Second, third, fourth gravidae

- Vertex presentation

- Delivery without episiotomy

- BT/CT is normal

- Spontaneous delivery

\section{Exclusion criteria}

- Traumatic PPH

- $\mathrm{PIH}$
- Cardiac disease

- Multiple pregnancy

- Induced delivery

- Primie gravidae

- Operative delivery

- Ante-partum haemorrhage

- Delivery with episiotomy

- If BT/CT is abnormal

- Pregnancy with previous c- section

Each patient had received i.m. oxytocin at the delivery of anterior shoulder of the baby, uterine massage for 4 minutes and placental delivery is done by controlled cord traction as prescribed by WHO. No other oxytocic has been administered except inj. Oxytocin 10IU i.m. unless patient develops PPH.

After delivery of baby all fluids/liquor/blood is immediately removed from the delivery table and a fresh specially prepared plastic sheet (brasss-V type) with funnel attached to its lower part replaced by the doctor. He has also collected the specially prepared $10 \times 10 \mathrm{cms}$ delivery pads soiled for visual assessment of blood loss. The total blood is collected in calibrated vessel after the delivery of the baby, delivery of placenta and through the 4th stage of labour (1hour).

The frequency of observation of blood loss is grouped in following categories.

0-50ml, 51-100ml, 101-150ml, 151-200ml, 201-250ml, 251-300ml, 301-350ml, 351-400ml, 401-450ml, 451500ml, 501-550ml, 551-600ml. etc.

The total amount of blood loss is calculated as follows:

Blood collected in calibrated vessel plus soiled pads.

Soiled pads-quarter of pad soiled $=5 \mathrm{ml}$, half of pad soiled $=10 \mathrm{ml}, 3 / 4$ of pad soiled $=20 \mathrm{ml}$, fully soiled pad $=$ $30 \mathrm{ml})$.

The doctor has also observed the time lag between administration of the drug and contraction \& retraction of uterus and duration of the third stage of labour (after delivery of baby to complete delivery of placenta).

The observations for duration of third stage of labour are noted in minutes using stop clock. The doctor has also meticulously observed the side effects of the drugs mentioned in literature as well as other untoward effects and note temperature, pulse, BP, Respiration in case records. (Data sheet proforma attached for observations).

\section{Notes on safety \& risk reduction}

Inj. Oxytocin $10 \mathrm{IU}$ is found to be safe if given i.m. as shown by review of literature. If any patient develops haemorrhage in excess of $500 \mathrm{ml}$ or develops any 
hemodynamic deterioration, patient shall be managed as per routine therapeutic method immediately using other oxytocic (inj. methyl ergometrine, inj. Carboprost $250 \mathrm{mcg}$ tab. Misoprostol $600 \mathrm{mcg}$ ) surgical methods and intravenous fluids if required to ensure safety of the patient.

\section{RESULTS}

Table 1: Demographic profile.

\begin{tabular}{|ll|}
\hline Factors & $\mathbf{N = 1 0 0}$ \\
\hline Age (years) & \\
\hline $24-29$ & 51 \\
\hline $30-35$ & 19 \\
\hline Area & \\
\hline Urban & 58 \\
\hline Rural & 42 \\
\hline Religion & \\
\hline Hindu & 91 \\
\hline Muslim & 09 \\
\hline Parity & \\
\hline Para 2 & 53 \\
\hline Para3 & 31 \\
\hline Para4 & 16 \\
\hline
\end{tabular}

In present study, Out of total 100 cases 51 patients $(51 \%)$ belonged to 24-29 years group and 30\% belonged to 1823 yrs of group, and $19 \%$ belonged to $>30$ years of age group. Mean age was 25.9 years. Majority 58\% of participants belong to urban area, $42 \%$ belong to rural area. Since the medical college located in city, majority of patients are from city area. In present study, 53patients $(53 \%)$ belonged to parity 2, $31 \%$ belongs to parity 3 and $16 \%$ were of parity 4 . Median parity was 2 .

Table 2: Association of duration of 3rd stage of labour (in minutes) and blood loss.

\begin{tabular}{|c|c|c|c|}
\hline \multicolumn{2}{|c|}{$\begin{array}{l}\text { Duration of third stage of } \\
\text { labour (minutes) }\end{array}$} & \multicolumn{2}{|c|}{ Blood loss (M.L.) } \\
\hline$<5$ & & 90 & \\
\hline $6-10$ & & 123 & \\
\hline$>10$ & & 335 & \\
\hline $\begin{array}{l}\text { Duration of } 3^{\text {rd }} \\
\text { stage of Labour } \\
\text { (minutes) }\end{array}$ & $\begin{array}{l}\text { Blood loss } \\
<200 \mathrm{ml}\end{array}$ & $\begin{array}{l}\text { Blood loss } \\
>200 \mathrm{ml}\end{array}$ & Total \\
\hline$\leq 4$ & 50 & 00 & 50 \\
\hline$\geq 5$ & 31 & 19 & 50 \\
\hline
\end{tabular}

Mean duration of third stage of labour was 5.16minutes.With AMTSL duration of third stage of labour shortened out. $98 \%$ of the participants had duration of third stage of labour $<10$ minutes. This proves the efficacy of AMTSL. In an investigation by Magann et al. the median length of the third stage of labor was 7 minutes. Jerbi et al. recommended the use of oxytocin in order to shorten the third stage and prevent PPH and blood loss. Armbruster and Fullerton showed that cord drainage could reduce the length of the third stage. Soltani et al. also believe there is a small reduction in the length of the third stage of labor when cord drainage is applied. The association between duration of third stage of labour and blood loss is considered to be extremely statistically significant.

Table 3: Blood loss observed during study.

\begin{tabular}{|ll|}
\hline Blood loss (In ML) & Frequency $(\mathbf{n}=\mathbf{1 0 0})$ \\
\hline$<50$ & 21 \\
\hline $51-100$ & 39 \\
\hline $101-150$ & 14 \\
\hline $151-200$ & 07 \\
\hline $201-250$ & 14 \\
\hline $251-300$ & 01 \\
\hline $301-350$ & 01 \\
\hline $351-400$ & 02 \\
\hline $401-450$ & 00 \\
\hline $451-500$ & 00 \\
\hline$>500$ & 01 \\
\hline
\end{tabular}

Mean blood loss in present study group was $119.4 \mathrm{ml}$.

Table 4: Side effects of inj. oxytocin in present study.

\begin{tabular}{|ll|}
\hline Side effects & No. of Patients $(\mathbf{n}=\mathbf{1 0 0})$ \\
\hline Shivering & 03 \\
\hline Nausea & 02 \\
\hline Vomiting & 01 \\
\hline Fever & 00 \\
\hline Hypertension & 00 \\
\hline Hypersensitivity & 00 \\
\hline
\end{tabular}

Shivering and nausea were most common side effects of inj. Oxytocin observed during present study.

Table 5: Association of baby weight with mean blood loss.

Baby weight (in K.G.) Mean blood loss (in ML)

\begin{tabular}{ll}
$1.5-2.0$ & 55 \\
\hline $2.1-2.5$ & 79 \\
\hline $2.6-3.0$ & 94 \\
\hline $3.1-3.5$ & 175 \\
\hline $3.6-4.0$ & 186 \\
\hline$>4.1$ & 330 \\
\hline
\end{tabular}

The association between Baby weight and blood loss is statistically considered as extremely significant. As the baby weight increases, the blood loss will also increase.

\section{DISCUSSION}

The purpose of the study is to evaluate the efficacy of AMTSL in active management of third stage of labour for prevention of post-partum haemorrhage [by measuring blood loss], duration of $3^{\text {rd }}$ stage of labour and 
side effects of oxytocin. The Chi square test was used for comparison between proportions. The main result was a significant reduction of blood loss. We found that Mean blood loss was $119 \mathrm{ml}$. No maternal deaths caused by PPH were observed during the study period. Incidence of PPH was reduced after the introduction of AMTSL. No maternal deaths caused by PPH were observed during the study period. The association between $3^{\text {rd }}$ stage of labour and blood loss is statistically considered as extremely significant. Longer the duration of third stage, more will be the blood loss. The association between Baby weight and blood loss is statistically considered as extremely significant. According to earlier research, high birth weight has significant influence on $\mathrm{PPH} .{ }^{18}$ One patient had PPH and blood transfusion was given after delivery. Shivering was the most common side effect observed during the study. Nausea and vomiting were other side effects observed. No other side effects e.g. water intoxication, hypersensitivity, hypertension was observed during this study. No SAE (serious adverse event) or serious ADR (adverse drug reaction) is reported in our study.

\section{CONCLUSIONS}

We recommend that following method must be employed for prevention of Post Partum hemorrhage as tested in our study and also prescribed by WHO for active management of $3^{\text {rd }}$ and $4^{\text {th }}$ stage of labor,

1. Controlled cord traction

2. Optimum uterine massage

3. inj. Oxytocin $10 \mathrm{IU}$ i.m. at delivery of anterior shoulder.

Active Management of Third Stage of Labour (AMTSL) significantly reduces chances of atonic PPH. AMTSL as a routine protocol significantly brings down incidence of $\mathrm{PPH}$.

Funding: No funding sources

Conflict of interest: None declared

Ethical approval: The study was approved by the Institutional Ethics Committee

\section{REFERENCES}

1. TajMahal History and Pictures at http:// www.indianchild.com/taj_mahal.html.

2. Post partumhemorrhage. Wed, Sept 21, 2011 Available from: URL: http://www.internationalmidwives.org/Projects/POP $\mathrm{PHI} /$ PostP artumHaemorrhage/tabid/339/Default.aspx

3. AbouZahr C. Global burden of maternal death and disability. Br Med Bull. 2003;67(1):1-11.

4. AbouZahr C, Wardlaw T. Maternal mortality at the end of a decade: signs of progress? Bulletin of the World Health Organization. 2001;79:561-8.
5. Li XF. The postpartum period: the key to maternal mortality. International Journal of Gynecology and Obstetrics. 1996;54:1-10.

6. WHO; Recommendations for the Prevention of Postpartum Hemorrhage. sec1:4; page 2.

7. Prendiville WJ, Elbourne D, McDonald S. Active versus expectant management in the third stage of labour. Cochrane Database. Syst. Rev. 2000, Issue 3.

8. Jennifer B, Ndola P, Jill D, Martine H. Proposal For The Inclusion Of Misoprostol In The Who Model List Of Essential Medicines; 17th Expert Committee on the Selection and Use of Essential Medicines Geneva, March. 2009;page5,6.

9. WHO. 2012. WHO recommendations for the prevention and treatment of postpartum haemorrhage.WHO:Geneva.http://www.who.int/repr oductivehealth/publications/maternal_perinatal_healt h/9789241548502/en/index.html.

10. Prendiville WJ, Harding JE, Elbourne DR, StirratGM. The Bristol third stage trial: active versus physiological management of the third stage of labor. Br Med J. 1988;297:1295-300.

11. Rogers J, Wood J, McCandlish R, Ayers S, TruesdaleA, Elbourne D. Active versus expectant management of third stage of labor: the Hinchingbrooke randomized controlled trial. Lancet 1998;351:693-9.

12. Khan GQ, John IS, Wani S, Doherty T, Sibai BM. Controlled cord traction versus minimal intervention techniques in delivery of the placenta: a randomized controlled trial. Am J ObstetGynecol. 1997;177:7704.

13. Kodkany BS, Derman RJ. A textbook of postpartum hemorrhage: a comprehensive guide to evaluation,management and surgical intervention; special FOGSI ed.jaypee brothers. 2006;1(4):35-41.

14. Williams JW. The tolerance of freshly delivered women to excessive loss of blood. Am J ObstetGynecol. 1919;90:1

15. Duthie SJ, Ven D, Yung GL, Guang DZ, Chan SY, Ma HK. Discrepancy between laboratory determination and visual estimation of blood loss during normal delivery.Eur J ObstetGynecolReprodBiol. 1990;38:119-24.

16. Patel A, Goudar SS, Geller SE. Drape esti- mation versus visual assessment for estimating postpartum hemorrhage. Int J Gynaecol Obstet. 2006;93:220-4.

17. Geller SE, Patel A, Naik VA. Conduct- ing international collaborative research in devel- oping nations. Int J Gynaecol Obstet. 2004;87:267-71.

18. Hofmeyr GJ. Evidence-based intrapartum care. Best Pract Res ClinObstetGyn- aecol. 2005;19:103-5.

Cite this article as: Patel M. A study on active management of third stage of labour as per WHO guidelines: efficacy and complications. Int J Reprod Contracept Obstet Gynecol 2016;5:80-3. 